\title{
Perspectivas sistemáticas de Zamia (Zamiaceae) en Megaméxico: de la taxonomía alfa a los códigos de barras genéticos
}

\section{Systematic perspectives on Zamia (Zamiaceae) in Megamexico: from alpha taxonomy to genetic barcodes}

\author{
Fernando Nicolalde-Morejón ${ }^{1 *}$, Jorge González-Astorga ${ }^{2}$, Francisco Vergara-Silva ${ }^{3}$ y Andrew P. Vovides ${ }^{4}$ \\ ${ }^{I}$ Instituto de Investigaciones Biológicas, Universidad Veracruzana. Av. Luis Castelazo Ayala s/n, Col. Industrial Ánimas, 91190 Xalapa, Veracruz, \\ México. \\ ${ }^{2}$ Laboratorio de Genética de Poblaciones, Departamento de Biología Evolutiva, Instituto de Ecología, A. C. Km. 2.5 Antigua Carretera a Coatepec \\ 351, 91070 Xalapa, Veracruz, México. \\ ${ }^{3}$ Laboratorio de Sistemática Molecular, Jardín Botánico, Instituto de Biología, Universidad Nacional Autónoma de México. Ciudad Universitaria, \\ Coyoacán, 04510 México D. F., México. \\ ${ }^{4}$ Laboratorio de Biología Evolutiva de Cycadales, Departamento de Biología Evolutiva, Instituto de Ecología, A. C, Km. 2.5 Antigua Carretera a \\ Coatepec 351, 91070 Xalapa, Veracruz, México. \\ *Correspondent:f_nicolalde@yahoo.com
}

\begin{abstract}
Resumen. El género Zamia en Megaméxico cuenta con 22 especies descritas y una entidad en el estatus de species dubium (Z. verschaffeltii). En las últimas décadas, el género Zamia ha recibido atención en tratamientos florísticos regionales, y de manera sobresaliente en una monografía especializada. Además, algunas especies del género han sido objeto de varios estudios recientes en citogenética, ecología y genética de poblaciones. El objetivo de este trabajo es presentar información actualizada sobre las especies de Zamia que se distribuyen en Megaméxico, con base en una revisión de ejemplares de herbario y trabajo de campo. Adicionalmente, se hace énfasis en los complejos de especies que aún requieren investigación para el esclarecimiento de sus límites taxonómicos. La discusión plantea la necesidad de realizar investigación en el aspecto poblacional con datos moleculares, mediante códigos de barras de $\operatorname{ADN}(D N A$ barcoding). Se concluye que la creación de una base de datos moleculares que funcione como "biblioteca de referencia de códigos de barras" para todas las especies de Zamia en Megaméxico sería de utilidad en aspectos sistemáticos, dentro de los cuales destaca la automatización de la identificación de especies, tanto en el campo como en colecciones biológicas. Dicha base de datos daría servicio a múltiples sectores sociales que son usuarios del conocimiento taxonómico especializado - por ejemplo, la industria forestal, las aduanas e instancias conservacionistas interesadas en diagnosticar especies de manera rápida y confiable, especialmente ante el tráfico ilegal de ejemplares.
\end{abstract}

Palabras clave: diversidad, DNA barcoding, Megaméxico, taxonomía.

\begin{abstract}
The genus Zamia in Megamexico includes 22 described species and one entity in the species dubium category (Z. verschaffeltii). During the last 2 decades, the genus Zamia has received attention in regional floristic treatments and, outstandingly, in a specialized monograph. Besides, some species in the genus have been the focus of several recent cytogenetic, ecological and population genetic studies. The objective of this work is to present updated information on the species of Zamia distributed in Megamexico, on the basis of a revision of herbarium specimens and fieldwork data. In addition, we emphasize that research is needed in some species complexes, in order to clarify their taxonomic limits. We discuss the need to conduct population-level research with molecular data, according to the DNA barcoding approach. We conclude that the creation of a molecular database that functions as a 'DNA barcodes reference library' for all Zamia species will be useful for systematic aspects, particularly automatization of species identifications, both in the field and in biological collections. At the same time, such databases would be helpful for multiple social sectors that employ specialized taxonomic knowledge -for instance, the forestry industry, customs and conservationist bodies interested in the rapid and reliable diagnosis of species, particularly in the face of illegal trade of specimens.
\end{abstract}

Key words: diversity, DNA barcoding, Megamexico, taxonomy. 


\section{Introducción}

El orden Cycadales consta de 3 familias: Cycadaceae, Stangeriaceae y Zamiaceae (Stevenson, 1992). Zamiaceae incluye, con ventaja, el mayor número de géneros descritos en el orden, y en el Neotrópico están presentes 5 géneros: Chigua D. W. Stev. y Microcycas (Miq.) A. DC., endémicos de Colombia y Cuba, respectivamente; Ceratozamia Brongn. y Dioon Lindl., endémicos de México, y Zamia L.

Zamia tiene 61 especies (Hill et al., 2007; Taylor et al., 2009), distribuidas desde Georgia y Florida en Estados Unidos, hasta Bolivia y el suroeste de Brasil (Balduzzi et al., 1982; Sabato, 1990; Norstog y Nicholls, 1997; Stevenson, 2001a); es también, uno de los géneros del orden Cycadales más difíciles de caracterizar (Norstog y Nicholls, 1997), debido a que sus patrones de variación morfológica, ecológica, citológica (Marchant, 1968; Vovides, 1983; Moretti y Sabato, 1984; Moretti, 1990; Moretti et al., 1991; Vovides y Olivares 1996; Norstog y Nicholls, 1997; Nicolalde-Morejón et al., 2009) y genética (González-Astorga et al., 2006; Limón, 2009) son muy complejos.

Históricamente, la primera monografía de Zamia incluyó 10 especies (Miquel, 1842). Posteriormente, se registraron 23 (Miquel, 1851; 1861) de las cuales, en la actualidad, 14 se consideran sinónimos (Hill et al., 2007). Más adelante, Schuster (1932) registró 26 especies. Varios trabajos taxonómicos (Stevenson, 1987; 1991a, b; 1993; 2001a, b; 2004; Sabato, 1990; Norstog y Nicholls, 1997; NicolaldeMorejón et al., 2008), así como la tipificación de nombres válidos (Stevenson y Sabato, 1986) han detectado errores nomenclaturales en la revisión de Schuster (1932), debidos principalmente al insuficiente trabajo de campo, a la escasa revisión de las colecciones botánicas y a los relativamente pocos ejemplares botánicos con estructuras reproductivas que existen en los museos y herbarios. De hecho, los caracteres diagnósticos para identificar las especies de Zamia están basados principalmente en atributos foliares, los cuales son muy variables. Esta circunstancia ha creado confusión en la delimitación y reconocimiento de las especies del género, lo cual se refleja directamente en un número considerable de sinonimias (Hill et al., 2007).

Sin embargo, en fechas recientes, el uso de caracteres de DNA como sitios diagnóstico, no sólo en cícadas sino en diversos grupos de gimnospermas y angiospermas, ha unido la sistemática molecular con la taxonomía tradicional, evidenciando que algunas regiones del genoma podrían comportarse de manera prácticamente invariable al interior de las poblaciones de una especie, al tiempo que podrían variar entre especies. El estudio de los patrones de variación en estas regiones genómicas, conocidos como códigos de barras de ADN (Hebert y Gregory, 2005), es de gran utilidad en la delimitación e identificación de especies. Esta perspectiva de análisis sustenta toda un área del conocimiento, como es la taxonomía molecular, y pretende establecer criterios moleculares en la identificación de especies (véase la página Bold Systems: www.boldsystems.org).

Por lo anterior, esta investigación conjuga las 2 fuentes de evidencia (i.e. morfológica y molecular) con la finalidad de definir atributos diagnósticos en la identificación de las especies endémicas del género Zamia (22) de Megaméxico 2, (Rzedowski, 1991), región que agrupa los territorios de México, Guatemala, Belice, El Salvador, y parte del norte de Nicaragua. En este sentido, se hace uso del concepto de Rzedowski simplemente como Megaméxico, dado que las diferencias entre los límites geográficos entre Megaméxico 1 con respecto a Megaméxico 2, no afectan los aspectos biogeográficos de nuestros análisis.

Con base en lo anterior, los objetivos de este trabajo son: a) determinar cuántas y cuáles especies de Zamia se distribuyen en Megaméxico; b) presentar un panorama histórico-taxonómico del género haciendo énfasis en los complejos de especies que se requiere estudiar con mayor profundidad o detalle, y c) discutir la utilidad de los códigos de barras de DNA para identificar y delimitar especies en el género.

\section{Materiales y métodos}

Trabajo de herbario y de campo. Para la realización de esta investigación se revisó el material botánico disponible en los siguientes herbarios: B, BM, CIB, CHIP, CICY, ECOSUR, ENCB, F, FCME, FLAS, FTG, HEM, IBUG, IEB, $\mathrm{K}$, LE, MEXU, MO, NY, SERO, U, UADY, UAMIZ, US, W, WIS, XAL, XALU y ZEA. La información se complementó con la consulta de las descripciones originales, así como de los tratamientos taxonómicos de todo el género. De manera paralela, durante los últimos 5 años se realizaron salidas de campo para recolectar material botánico y evaluar los atributos diagnósticos (morfológicos) previamente publicados para todas las especies.

Recolección de material biológico. Se recolectó tejido foliar de todas la especies de Zamia conocidas para Megaméxico de acuerdo con Nicolalde-Morejón et al. (2009) (Cuadro 1). La mayor parte del material se obtuvo de plantas vivas cultivadas en el Jardín Botánico Francisco Javier Clavijero del Instituto de Ecología, A. C., en Jalapa, Veracruz, y se realizaron recolecciones de campo para completar el muestreo (e. g. Zamia variegata). El Centro Botánico Montgomery (MBC) donó las muestras de $Z$. prasina, Z. standleyi y $Z$. tuerckheimii. En el caso de $Z$. onanreyesii, Z. oreillyi, Z. sandovallii y Z. monticola, especies de reciente descripción, no fue posible recolectarlas, 
Cuadro 1. Especies, distribución y tipos de vegetación de Zamia en Megaméxico

\begin{tabular}{|c|c|c|c|c|}
\hline & Especie & País & Estado/Departamento & $\begin{array}{l}\text { Tipo de } \\
\text { vegetación }\end{array}$ \\
\hline 1 & Z. cremnophila & México & Tabasco & BTP \\
\hline 2 & Z. fischeri & México & Hidalgo, Querétaro, San Luís Potosí & $\begin{array}{l}\text { BTsC, BMM, } \\
\text { BQ-BC }\end{array}$ \\
\hline 3 & Z. furfuracea & México & Veracruz & BTP \\
\hline 4 & Z. herrerae & $\begin{array}{l}\text { El Salvador, } \\
\text { Guatemala, México }\end{array}$ & ES: Sonsonate, M: Chiapas & BTP, BTsC \\
\hline 5 & Z. inermis & México & Veracruz & BTC \\
\hline 6 & Z. katzeriana & México & Chiapas, Tabasco, Veracruz & ВТP \\
\hline 7 & Z. lacandona & México & Chiapas & ВТP \\
\hline 8 & Z. loddigesii & México & $\begin{array}{l}\text { Chiapas, Hidalgo, Oaxaca, Puebla, Tabasco, } \\
\text { Tamaulipas, Veracruz }\end{array}$ & ВТР \\
\hline 9 & Z. monticola & Guatemala & Alta Verapaz & ВТР \\
\hline 10 & Z. onanreyesii & Honduras & Cortés & BTP \\
\hline 11 & Z. oreillyi & Honduras & Atlántida & ВTP \\
\hline 12 & Z. paucijuga & México & $\begin{array}{l}\text { Colima, Guerrero, Jalisco, Michoacán, } \\
\text { Nayarit, Oaxaca }\end{array}$ & $\begin{array}{l}\text { BTsC, } \\
\text { BTC, } \\
\text { BQ }\end{array}$ \\
\hline 13 & Z. polymorpha & $\begin{array}{l}\text { Belice, } \\
\text { Guatemala, } \\
\text { México }\end{array}$ & $\begin{array}{l}\text { B: Distrito Belice, Distrito Cayo; G: Peten; } \\
\text { M: Campeche, Chiapas, Quintana Roo, } \\
\text { Tabasco, Yucatán }\end{array}$ & $\begin{array}{l}\text { BTP, } \\
\text { BTsC }\end{array}$ \\
\hline 14 & Z. prasina & Belice & Distrito Toledo & BTP \\
\hline 15 & Z. purpurea & México & Oaxaca, Veracruz & BTP \\
\hline 16 & Z. sandovallii & Honduras & Atlántida & BTP \\
\hline 17 & Z. soconuscensis & México & Chiapas & BTsC \\
\hline 18 & Z. spartea & México & Oaxaca & $\begin{array}{l}\text { BTP, } \\
\text { BTC }\end{array}$ \\
\hline 19 & Z. standleyi & Guatemala, & G: Izabal; H: Atlántida, Santa Bárbara & ВТP \\
\hline 20 & Z. tuerckheimii & $\begin{array}{l}\text { Honduras } \\
\text { Guatemala }\end{array}$ & Alta Verapaz & ВТP \\
\hline 21 & Z. variegata & Guatemala, México & $\begin{array}{l}\text { G: Alta Verapaz, Izabal; } \\
\text { M: Chiapas }\end{array}$ & BTP \\
\hline 22 & Z. vazquezii & México & Veracruz & BTP \\
\hline
\end{tabular}

Tipos de vegetación (sensu Rzedowski, 1978): BTP, bosque tropical perennifolio; BTsC, bosque tropical subcaducifolio; BMM, bosque mesófilo de montaña; BQ, bosque de Quercus; BC, bosque de coníferas.

por lo que no se incluyen en el análisis.

Extracción y amplificación de DNA. La extracción del DNA se hizo con el método indicado por el fabricante del DNeasy® Plant Mini Kit (Qiagen). La inspección cualitativa de las muestras de DNA extraídas se realizó mediante electroforesis en geles de agarosa. Las reacciones de amplificación (PCR) se hicieron incluyendo todas las combinaciones de primers propuestos en la segunda Conferencia Internacional de Códigos de Barras de la Vida (Pennisi, 2007) y con base en trabajos previos en plantas 
(Sass et al., 2007; Fazekas et al., 2008; Lahaye et al., 2008; Hollingsworth et al., 2009). Dichas regiones del genoma corresponden a las secuencias que codifican las proteínas ribosomales $r p o C l$ y $r p o B$, las intergénicas $t r n H-p s b A$, $a t p F-a t p H$ y $p s b I-p s b K$ y la codificante de la maturasa $\mathrm{K}$ $(m a t K)$ y $r b c L$. También se exploraron las regiones del genoma nuclear que corresponden a los espaciadores intergénicos transcritos ITS, ITS1 e ITS2 (para más detalles, sobre estas regiones, véase Sass et al., 2007). En todos los casos donde se obtuvo una sola banda de amplificación, los PCR se purificaron mediante el uso de kits comerciales (QIAquick ${ }^{\circledR}$ PCR Purification Kit, Qiagen). Para el caso exclusivo del locus trnH-psbA fue necesario purificar desde las bandas de amplificación observadas en el gel de agarosa, debido a que siempre se obtuvieron 2 moléculas de diferente peso (observables como 2 bandas diferentes en los geles). El proceso de secuenciación se realizó a través de la empresa Macrogen (http://www.macrogen.com; para los números de accesión de GenBank, véase Cuadro 2). Análisis de datos. El ensamblaje y edición de las secuencias se realizaron con el programa Sequencher v. 4.8 (Gene Code Corp., Ann Arbor, Michigan, EUA). La alineación de las secuencias se efectuó con el programa Clustal X (Thompson et al. 1997) bajo el modo de alineamiento múltiple, a través de la interfase BioEdit 7.0.9 (Hall, 1999). Todos los archivos de las secuencias alineadas fueron almacenados en formato Nexus y luego exportados al programa MacClade (Sinauer Associates, Sunderland, Massachusetts, EUA). Los análisis en computadora para la identificación de caracteres diagnósticos para constituir los códigos de barras moleculares especie-específicos se realizaron con P-Gnome, que implementa la estrategia de identificación de sitios diagnósticos, conocido como: Sistema de Organización de Atributos Característicos (Characteristic Attribute Organization System o CAOS; Sarkar et al., 2008).

Cuadro 2. Números de accesiones de GenBank para los loci secuenciados en este estudio

\begin{tabular}{lcccccc}
\hline Taxa & psbI/K & atpF/H & rpoC1 & trnH-psbA & matK & ITS2 \\
\hline Zamia cremnophila & GU807217 & GU807158 & GU807296 & & GU807344 & GU807352 \\
Z. fischeri & GU807218 & GU807160 & GU807299 & GU807417 & & GU807354 \\
Z. furfuracea & GU807219 & GU807161 & GU807300 & GU807418 & GU807345 & GU807355 \\
Z. herrerae & GU807220 & GU807162 & GU807301 & GU807419 & GU807346 & GU807356 \\
Z. inermis & GU807221 & GU807163 & GU807302 & & GU807347 & \\
Z. katzeriana & GU807222 & GU807165 & GU807304 & GU807420 & & GU807358 \\
Z. lacandona & GU807223 & GU807166 & GU807305 & GU807421 & & GU807359 \\
Z. loddigesii & GU807224 & GU807167 & GU807306 & GU807422 & & GU807360 \\
Z. paucijuga & GU807225 & GU807169 & GU807308 & GU807423 & GU807348 & GU807362 \\
Z. polymorpha & GU807226 & GU807170 & GU807309 & & GU807349 & GU807363 \\
Z. prasina & GU807227 & GU807171 & GU807310 & & & GU807364 \\
Z. purpurea & GU807228 & GU807173 & GU807312 & GU807424 & GU807350 & GU807365 \\
Z. soconuscensis & GU807229 & GU807174 & GU807314 & GU807425 & & GU807366 \\
Z. spartea & GU807231 & GU807175 & GU807315 & GU807426 & GU807351 & GU807367 \\
Z. standleyi & GU807232 & GU807176 & GU807316 & & & GU807368 \\
Z. tuerckheimii & GU807230 & GU807177 & GU807317 & & & GU807369 \\
Z. variegata & GU807233 & GU807178 & GU807318 & GU807427 & & GU807370 \\
Z. & GU807234 & GU807179 & GU807319 & GU807428 & & GU807371 \\
\hline
\end{tabular}




\section{Resultados}

\section{Morfología y grupos afines}

Las especies de Zamia son dioicas, entomófilas y de larga vida, con distribución restringida al Neotrópico. Zamia tiene una amplia diversidad de formas y preferencias ecológicas: por ejemplo, mientras que la especie endémica colombiana Z. wallisii A. Braun posee folíolos fuertemente acanalados de hasta $15 \mathrm{~cm}$. de ancho con nervaduras conspicuas, Z. spartea A. DC -endémica de Oaxaca, México- tiene folíolos de hasta $1 \mathrm{~cm}$ de ancho, totalmente lisos. El género también incluye especies con tallos arbóreos; por ejemplo, Z. obliqua A. Braun (Colombia y Panamá) que llega a medir hasta $5 \mathrm{~m}$ de alto (Stevenson, 2004); en contraste, Z. paucijuga Wieland — también endémica de México (de Nayarit a Oaxaca) - y Z. amazonum D. W. Stev. - proveniente de la Amazonía de Colombia, Ecuador, Perú y Brasil- poseen tallos subterráneos. Además, Z. pseudoparasitica Yates in Seem. -endémica de Panamá, es la única especie epifita del orden (Stevenson, 1993).

Las especies de Zamia se encuentran en ambientes muy contrastantes, como es el caso de $Z$. gentryi Dodson, endémica de Ecuador (Nicolalde-Morejón, 2007), que se distribuye en bosques húmedos premontanos (Holdridge, 1978), con lluvias hasta de $6500 \mathrm{~mm}$ en promedio al año; Z. encephalartoides D. W. Stev., endémica de Colombia, crece en hábitats xéricos (Stevenson, 2004), mientras que Z. roezlii Linden, de la cual se conocen poblaciones del bosque húmedo tropical y en manglares, se distribuye sobre la planicie costera de Ecuador y Colombia.

Altitudinalmente, Zamia se distribuye desde el nivel del mar, sobre dunas costeras (Z. furfuracea L. f., México) hasta los $2700 \mathrm{~m}$, como ocurre con Z. montana A. Braun, especie endémica de bosques húmedos premontanos en Antioquia, Colombia (Stevenson, 2001a).

Tomando en cuenta la morfología, especialmente hábito, hojas y folíolos, de múltiples ejemplares del género Zamia (Vovides et al., 2007), y considerando que en Megaméxico existen varios complejos de especies, los cuales son de difícil identificación; por ejemplo, en el noreste de México (Tamaulipas, San Luís Potosí, Querétaro, Hidalgo y norte de Veracruz) existen 2 especies de apariencia similar: Z. fischeri Miq. y Z. vazquezii D. W. Stev., Sabato, A. Moretti y De Luca. Este par de especies, aquí denominado "complejo Zamia fischeri", incluye plantas generalmente pequeñas con folíolos papiráceos, dentaciones sobre los bordes de los folíolos y tallos subterráneos. Otros caracteres diagnósticos son atributos asociados a estructuras reproductivas femeninas (Nicolalde-Morejón et al., 2009). Por otro lado, en el sureste de México (Veracruz, Oaxaca,
Tabasco y Chiapas) se encuentra el complejo Zamia katzeriana, que incluye a $Z$. katzeriana (Regel) Retting, $Z$. cremnophila Vovides, Schutzman et Dehgan, Z. lacandona Schutzman et Vovides y Z. purpurea Vovides, J. D. Rees et Vázq. Torres, las cuales se caracterizan por sus folíolos anchos $(3-11 \mathrm{~cm})$ y coriáceos, y tallos subterráneos (Nicolalde-Morejón et al., 2008). Aunque Z. purpurea pertenece a este grupo, sus folíolos acanalados con nervaduras conspicuas - atributo único entre las especies en Megaméxico- la asemejan más al complejo basado en $Z$. skinneri Warsz. ex A. Dietrich, que se distribuye en Costa Rica, Panamá, Colombia y Ecuador.

El complejo Zamia loddigesii (Z. loddigesii Miq., Z. paucijuga y Z. polymorpha D. W. Stev., A. Moretti y Vázq. Torres) incluye las especies de mayor distribución en Megaméxico (Fig. 1), son también las que tienen los números cromosómicos más altos (Moretti, 1990), y morfológicamente son los taxa que presentan más dificultad para identificarse. Entre los atributos fenotípicos de este complejo están los folíolos coriáceos, linear-lanceolados a oblanceolados y con tallos subterráneos. Sin embargo, desde la misma perspectiva morfológico-vegetativa, $Z$. spartea -endémica del ístmo de Tehuantepec, Oaxaca, México-y Z. prasina W. Bull —endémica de Belice-, deberían ser incluidas en este complejo, para posteriores estudios taxonómico y evolutivos. Si bien, entre especies del grupo compuesto por Z. tuerckheimii Donn. Sm. (Guatemala), Z. soconuscensis Schutzman, Vovides y Dehgan (Chiapas, México) y Z. inermis Vovides, J. D. Rees et Vázq. Torres (Veracruz, México) no existen problemas para su identificación, éstas comparten caracteres, como los tallos epigeos y los folíolos con los bordes enteros; no obstante, debido a la presencia de folíolos linear-lanceolados, coriáceos y bordes enteros, los ejemplares de herbario de $Z$. inermis (usualmente carentes de estructuras reproductivas) podrían confundirse con ejemplares de $Z$. encephalartoides. Además es necesario considerar a $Z$. onanreyesii $\mathrm{C}$. Nelson et G. Sandoval, especie que también tiene tallos aéreos de hasta $2 \mathrm{~m}$ de alto, pero que a diferencia de las anteriores posee folíolos subcoriaceos y márgenes serrulados sobre el tercio distal.

Las especies Z. oreillyi C. Nelson, Z. sandovallii C. Nelson y Z. standleyi Schutzman, de reciente descripción, se caracterizan por tener folíolos lisos, subcoriaceos, bordes serrulados a dentados y tallos subterráneos, todas se distribuyen en una misma región (Honduras y Guatemala). Como la identificación y delimitación de estas especies con base en caracteres morfológicos vegetativos y reproductivos no es problemática, no existen dificultades taxonómicas asociadas a este grupo. Finalmente, Z. variegata Warsz. y $Z$. furfuracea son especies fáciles de caracterizar e identificar. Zamia variegata tiene folíolos variegados por el haz, 
atributo único dentro del género Zamia; en tanto que $Z$. furfuracea presenta tallos aéreos generalmente bifurcados, folíolos coriáceos abovados a oblanceolados con indumento amarillento. Esta última crece sobre dunas costeras en la región centro-sur del estado de Veracruz.

\section{Megaméxico, diversidad y endemismo}

Considerando las 22 especies de Zamia conocidas actualmente para Megaméxico (Nicolalde-Morejón et al., 2009), México cuenta con 12 especies endémicas - la mayor diversidad para la región- seguido por Honduras con 3, Guatemala con 2, y Belice con 1 (Cuadro1). En Megaméxico se encuentran 2 centros de mayor diversidad (Fig. 1), el primero, ubicado en el sureste de México (sur de Veracruz, Tabasco, sureste de Oaxaca y norte de Chiapas), con 7 especies, todas simpátricas (Z. cremnophila, Z. katzeriana, Z. lacandona, Z. loddigesii, Z. purpurea, Z. polymorpha y $Z$. spartea), y el segundo, entre Guatemala (Alta Verapaz e Izabal) y Honduras (Atlántida, Cortés y Santa Bárbara), con 7 especies (Z. monticola Chamb., $Z$. onanreyesii, Z. oreillyi, Z. sandovallii, Z. standleyi, $Z$. tuerckheimii y Z. variegata). Estos sitios tienen un clima cálido húmedo donde la temperatura promedio anual es de $25^{\circ} \mathrm{C}$ y la precipitación de 3000 a $4000 \mathrm{~mm}$ por año (Toledo, 1982); ambos comparten tipos similares de vegetación, particularmente bosque tropical perennifolio (Rzedowski, 1978).

Estos datos de acumulación de diversidad de Zamia contrastan con los de áreas como la planicie costera del Pacífico, donde se registran únicamente 3 especies $(Z$. herrerae Calderon y Standl., Z. paucijuga y Z. soconuscensis) a lo largo de aproximadamente $2000 \mathrm{~km}$ desde Nayarit (México) hasta El Salvador. Esta amplia zona está asociada a diferentes tipos de vegetación, como bosque tropical perennifolio, bosque tropical subcaducifolio, bosque de coníferas y de Quercus (Rzedowski, 1978). Algo similar pasa en la península de Yucatán (México), el Petén en Guatemala y parte de Belice, donde se distribuye únicamente Z. polymorpha (Fig. 1).

Intensidad de las recolecciones botánicas. En términos de recolecciones botánicas realizadas hasta la fecha, los 2 sitios de alta concentración de riqueza de especies están poco representados. Por ejemplo, sólo hay 8 para Z. cremnophila, de la primera región, y 6 para Z. tuerckheimii de la segunda. En contraste, las especies más recolectadas son Z. polymorpha (ca. 100 recolecciones), Z. paucijuga (ca. 114) y Z. loddigesii (ca. 80), todas de amplia distribución (Cuadros 3 y 4). A la vez, debe notarse que sólo

Cuadro 3. Número de colectas botánicas de Zamia en Megaméxico depositadas en herbarios de México

\begin{tabular}{|c|c|c|c|c|c|c|c|c|c|c|c|c|c|c|c|c|}
\hline \multirow[b]{2}{*}{ Taxa } & \multicolumn{16}{|c|}{ Herbarios en México } \\
\hline & 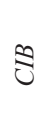 & $\underset{\Xi}{\Xi}$ & 仓ે & 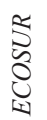 & $\sum_{\substack{0 \\
0}}^{8}$ & 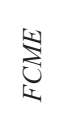 & 起 & 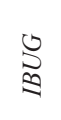 & 图 & 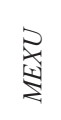 & 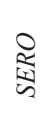 & $\underset{S}{\stackrel{S}{S}}$ & $\underset{S}{\stackrel{S}{S}}$ & ฟै & $\underset{7}{D}$ & 过 \\
\hline Z. cremnophila & & & & & & 1 & 2 & & & 2 & & & 1 & 1 & & \\
\hline Z. fischeri & & & & & & 1 & & & & 6 & & & & 16 & & \\
\hline Z. furfuracea & & & & & & & & & & & & & & 23 & & \\
\hline Z. herrerae & 1 & 1 & & & & & 1 & & & 4 & & & & 5 & & \\
\hline Z. inermis & & & & & & & & & & & & & & 11 & & \\
\hline Z. katzeriana & 1 & 3 & & & & 1 & & & & 4 & & & & 19 & & \\
\hline Z. lacandona & 1 & & & & 1 & & 1 & & & 2 & & & & 19 & & \\
\hline Z. loddigesii & 4 & 1 & & & & 1 & 1 & & & 12 & & & & 56 & 1 & 1 \\
\hline Z. paucijuga & 1 & & & & & 12 & & 10 & & 8 & 1 & & 3 & 74 & & 7 \\
\hline Z. polymorpha & & & 2 & & & & & & & 8 & & 4 & & 40 & & \\
\hline Z. purpurea & 4 & & & & & & & & & 1 & 1 & & & 9 & & \\
\hline Z. sandovallii & & & & & & & & & & & & & & & & \\
\hline Z. soconuscensis & 1 & 1 & & & & & 1 & & & 7 & & & & & & \\
\hline Z. spartea & 2 & & & & & & & & & 1 & 1 & & 1 & 19 & & \\
\hline Z. variegata & 1 & & & & & & & & & & & & & 15 & & \\
\hline Z. vazquezii & 2 & & & & & & & & & & & & & 2 & & \\
\hline
\end{tabular}

Nota: Z. monticola, Z. onanreyesii, Z. oreillyi, Z. prasina, Z. standleyi y Z. tuerckheimii no constan en este cuadro, debido a que ninguno de los herbarios de México que se revisaron cuenta con algún registro para las especies señaladas. 
Cuadro 4. Número de colectas botánicas de Zamia en Megaméxico depositadas en herbarios extranjeros

\begin{tabular}{|c|c|c|c|c|c|c|c|c|c|c|c|c|c|c|}
\hline \multirow[b]{2}{*}{ Taxa } & \multicolumn{14}{|c|}{ Herbarios } \\
\hline & $C R$ & $F$ & $F L A S$ & $F T G$ & $K$ & $L E$ & $\mathrm{MICH}$ & $M O$ & $N Y$ & $O X$ & TEFH & $U$ & $U S$ & $W$ \\
\hline Z. cremnophila & & & & & & & & 1 & & & & & & \\
\hline Z. fischeri & & & & & & & & 1 & 1 & & & 1 & & \\
\hline Z. furfuracea & & 2 & & & & & & 4 & & & & & & \\
\hline Z. herrerae & & 1 & & & & & & 1 & & & & & 1 & \\
\hline Z. inermis & & 1 & & & & & & & & & & & & \\
\hline Z. katzeriana & & & 1 & 2 & & 1 & & & 1 & & & & & \\
\hline Z. lacandona & & & 1 & 1 & & & & & & & & & & \\
\hline Z. loddigesii & & & & & 1 & 1 & & 3 & 3 & 1 & & 3 & & \\
\hline Z. monticola & & & & & & & & 1 & 2 & & & & & \\
\hline Z. onanreyesii & & & 1 & & & & & & & & 3 & & & \\
\hline Z. oreillyi & & & & & & & & & 1 & & 2 & & & \\
\hline Z. paucijuga & & & & 2 & & & & 2 & & & & & & \\
\hline Z. polymorpha & & & & 3 & 1 & & & 15 & 6 & & & 3 & & \\
\hline Z. prasina & & & & & 1 & & & 2 & & & & & & \\
\hline Z. purpurea & & & & 1 & & & & 2 & & & & & & \\
\hline Z. sandovallii & & & & & & & & & & & 4 & & & \\
\hline Z. soconuscensis & 1 & 1 & & & & & 1 & & & & & & & \\
\hline Z. spartea & & & & 1 & & & & & & & & & & \\
\hline Z. standleyi & & 3 & 1 & 1 & & & & & 2 & & & & 2 & 1 \\
\hline Z. tuerckheimii & & & & & 1 & & & 2 & & & & & 1 & 2 \\
\hline Z. variegata & & & & & & & & & 2 & & & 1 & & \\
\hline Z. vazquezii & & & & 1 & & & & 1 & 2 & & & 1 & & \\
\hline
\end{tabular}

una pequeña parte de su distribución converge con las áreas de alta riqueza, como sucede con $Z$. loddigesii y $Z$. polymorpha (Fig. 1). Es posible que este patrón se deba al hecho de que las especies menos colectadas tienen áreas de distribución muy restringidas y en muchos casos sólo se conocen de la localidad tipo, y a que las especies de amplia distribución, como Z. loddigesii, Z. paucijuga y $Z$. polymorpha se encuentran en áreas de fácil acceso e históricamente han sido recolectadas con amplitud.

Códigos de barras genéticos para Zamia en Megaméxico Exito en la amplificación en el grupo de estudio. De los loci ensayados para el genoma del cloroplasto, 5 amplificaron satisfactoriamente en Zamia: rpoC1, rbcL, trnH-psbA, $a t p F-a t p H$ y $p s b I-p s b K$. La pareja de primers matK presentó problemas de amplificación para algunas especies, mientras que en los primers para el locus $r p o B$ no hubo amplificación alguna. En cuanto a los loci nucleares, si bien no se tuvo éxito con la amplificación del fragmento completo de ITS (18S-26S), posteriores ensayos confirmaron una buena amplificación del fragmento ITS2.

Sitios diagnósticos moleculares en Zamia. De los 8 loci que amplificaron en Zamia, rbcL y trnH-psbA no presentan sitios diagnósticos que permita la discriminación entre especies. Los análisis de sitios diagnostico según CAOS (Sarkar et al., 2008) muestran que los espaciadores intergénicos de cloroplasto $p s b I-p s b K$ y atpF-atpH son las regiones que presentaron mayor número de sitios diagnóstico, lo cual permite discriminar el 50\% (9/18) de las especies aquí analizadas; en tanto, que la adición del espaciador interno transcrito ITS2 incrementa el porcentaje de identificación al 67\% (12/18), finalmente con la inclusión 


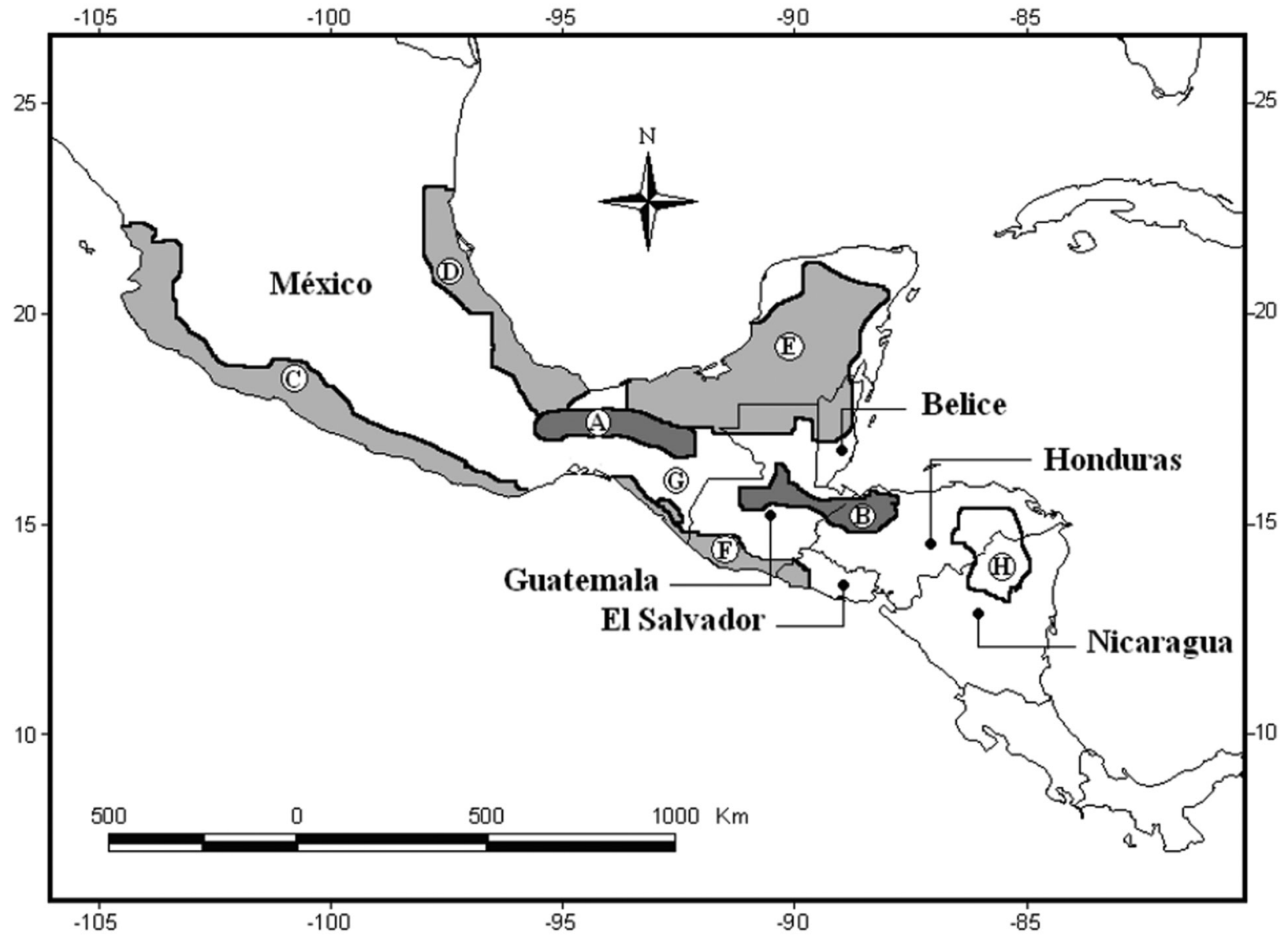

Figura 1. Distribución de: A). Zamia cremnophila, Z. katzeriana, Z. lacandona, Z. purpurea, Z. spartea; B). Z. monticola, Z. onareyesii, Z. oreillyi, Z. sandovallii, Z. standleyi, Z. tuerckheimii, Z. variegata; C). Z. paucijuga; D). Z. loddigesii; E). Z. polymorpha; F). Z. herrerae; G). Z. soconuscensis; H). Área inexplorada para Zamia.

de rpoCl y matK Kew (sólo considerando las especies de Zamia en las que se obtuvo buena amplificación y secuencias), se llega al 72\% (13/18) de éxito de identificación de las especies de Zamia en Megaméxico. (Cuadros 5 y 6).

\section{Discusión}

Perspectivas del género Zamia en Megaméxico. Considerando la historia nomenclatural y la complejidad morfológica de las especies de Zamia, el complejo Zamia loddigesii es claramente sobresaliente. Se trata de un grupo que requiere de una investigación detallada que permita aclarar su circunscripción taxonómica y nomenclatural, como se detalla a continuación. Z. loddigesii es sin duda la especie más compleja desde el punto de vista nomen- clatural, con un total de 12 nombres afines y con varias sinonimias (Nicolalde-Morejón et al., 2009). A pesar de ser una especie colectada ampliamente a lo largo del golfo de México, desde el siglo XIX hasta hoy, se desconocía la existencia de algún ejemplar de herbario que pudiera fungir como tipo nomenclatural, por lo que Stevenson y Sabato (1986) habían lectotipificado el protólogo. Sin embargo, en investigaciones recientes se muestra un ejemplar (i.e. van Houtte 3374 [U]]) que fue colectado previo a la descripción de la especie, y que concuerda con los atributos morfológicos descritos por Miquel en 1843. Por esta razón, dicho ejemplar ha sido considerado para su designación como lectotipo de esta especie (Nicolalde-Morejón et al., 2009, Cuadro 7).

En contraste, aunque taxonómicamente no han experimentado cambio alguno, Z. paucijuga y Z . polymorpha, junto a $Z$. loddigesii, son las especies catalogadas como 
Cuadro 5. Sitios diagnósticos con $p s b K-p s b I$, rpoCl y atpF-atpH, para Zamia en Megaméxico

\begin{tabular}{|c|c|c|c|c|c|c|c|c|c|c|c|c|c|c|c|c|c|c|}
\hline \multirow[b]{2}{*}{ Taxa } & \multicolumn{10}{|c|}{$p s b I-p s b K$} & \multicolumn{4}{|c|}{ rpoCl } & \multicolumn{4}{|c|}{$a t p F-a t p H$} \\
\hline & 44 & 53 & 123 & 208 & 232 & 331 & 420 & 448 & 521 & 577 & 74 & 458 & 54 & 186 & 270 & 353 & 456 & 472 \\
\hline Z. cremnophila & $\mathrm{T}$ & $\mathrm{T}$ & A & A & $\mathrm{C}$ & $\mathrm{T}$ & $\mathrm{T}$ & $\mathrm{T}$ & $\mathrm{T}$ & $\mathrm{C}$ & $\mathrm{T}$ & $\mathrm{T}$ & - & $\mathrm{C}$ & $\mathrm{C}$ & G & $\mathrm{T}$ & G \\
\hline Z. fischeri & $\mathrm{T}$ & $\mathrm{T}$ & A & A & $\mathrm{C}$ & $\mathrm{T}$ & $\mathrm{T}$ & $\mathrm{T}$ & $\mathrm{T}$ & $\mathrm{C}$ & $\mathrm{T}$ & $\mathrm{T}$ & $\mathbf{A}$ & $\mathrm{C}$ & $\mathbf{T}$ & G & $\mathrm{T}$ & G \\
\hline Z. furfuracea & $\mathrm{T}$ & $\mathrm{T}$ & A & A & $\mathrm{C}$ & $\mathrm{T}$ & $\mathrm{T}$ & $\mathrm{T}$ & $\mathrm{T}$ & $\mathrm{C}$ & $\mathrm{T}$ & $\mathrm{T}$ & - & $\mathrm{C}$ & $\mathrm{C}$ & G & $\mathrm{T}$ & G \\
\hline Z. herrerae & $\mathrm{T}$ & $\mathrm{T}$ & A & A & $\mathrm{C}$ & $\mathrm{T}$ & $\mathrm{T}$ & $\mathrm{T}$ & $\mathrm{T}$ & $\mathrm{C}$ & $\mathrm{T}$ & $\mathrm{T}$ & - & $\mathrm{C}$ & $\mathrm{C}$ & G & G & G \\
\hline Z. inermis & $\mathrm{T}$ & $\mathrm{T}$ & A & A & $\mathrm{C}$ & $\mathrm{T}$ & $\mathrm{T}$ & $\mathrm{T}$ & $\mathrm{T}$ & $\mathbf{T}$ & $\mathrm{T}$ & $\mathrm{T}$ & - & $\mathrm{C}$ & $\mathrm{C}$ & G & $\mathrm{T}$ & G \\
\hline Z. katzeriana & $\mathrm{T}$ & $\mathrm{T}$ & A & A & $\mathrm{C}$ & $\mathrm{T}$ & $\mathrm{T}$ & $\mathrm{T}$ & $\mathrm{T}$ & $\mathrm{C}$ & $\mathrm{T}$ & $\mathrm{T}$ & - & $\mathrm{C}$ & $\mathrm{C}$ & G & $\mathrm{T}$ & G \\
\hline Z.lacandona & $\mathrm{T}$ & $\mathrm{T}$ & $\mathrm{A}$ & A & $\mathrm{C}$ & $\mathrm{T}$ & $\mathrm{T}$ & $\mathbf{C}$ & $\mathrm{T}$ & $\mathrm{C}$ & C & $\mathrm{T}$ & - & $\mathbf{A}$ & $\mathrm{C}$ & G & $\mathrm{T}$ & G \\
\hline Z. loddigesii & $\mathrm{T}$ & $\mathrm{T}$ & A & G & $\mathrm{C}$ & $\mathrm{T}$ & G & $\mathrm{T}$ & $\mathrm{T}$ & $\mathrm{C}$ & $\mathrm{T}$ & $\mathrm{T}$ & - & $\mathrm{C}$ & $\mathrm{C}$ & G & $\mathrm{T}$ & G \\
\hline Z. paucijuga & $\mathrm{T}$ & $\mathrm{T}$ & A & A & $\mathrm{C}$ & $\mathrm{T}$ & $\mathrm{T}$ & $\mathrm{T}$ & $\mathrm{T}$ & $\mathrm{C}$ & $\mathrm{T}$ & $\mathrm{T}$ & - & $\mathrm{C}$ & $\mathrm{C}$ & G & $\mathrm{T}$ & G \\
\hline Z. polymorpha & C & $\mathrm{T}$ & G & A & $\mathrm{C}$ & $\mathbf{C}$ & $\mathrm{T}$ & $\mathrm{T}$ & $\mathrm{T}$ & $\mathrm{C}$ & $\mathrm{T}$ & $\mathrm{T}$ & - & $\mathrm{C}$ & $\mathrm{C}$ & G & $\mathrm{T}$ & G \\
\hline Z. prasina & $\mathrm{T}$ & C & A & A & $\mathrm{C}$ & $\mathrm{T}$ & $\mathrm{T}$ & $\mathrm{T}$ & $\mathrm{T}$ & $\mathrm{C}$ & $\mathrm{T}$ & $\mathrm{T}$ & - & $\mathrm{C}$ & $\mathrm{C}$ & $\mathbf{A}$ & $\mathrm{T}$ & G \\
\hline Z. purpurea & $\mathrm{T}$ & $\mathrm{T}$ & A & A & $\mathrm{C}$ & $\mathrm{T}$ & $\mathrm{T}$ & $\mathrm{T}$ & $\mathrm{T}$ & $\mathrm{C}$ & $\mathrm{T}$ & $\mathrm{T}$ & - & $\mathrm{C}$ & $\mathrm{C}$ & G & $\mathrm{T}$ & G \\
\hline Z. soconuscensis & $\mathrm{T}$ & $\mathrm{T}$ & A & A & $\mathrm{C}$ & $\mathrm{T}$ & $\mathrm{T}$ & $\mathrm{T}$ & $\mathrm{T}$ & $\mathrm{C}$ & $\mathrm{T}$ & $\mathbf{C}$ & - & $\mathrm{C}$ & $\mathrm{C}$ & G & $\mathrm{T}$ & $\mathbf{T}$ \\
\hline Z. spartea & $\mathrm{T}$ & $\mathrm{T}$ & A & A & $\mathrm{C}$ & $\mathrm{T}$ & $\mathrm{T}$ & $\mathrm{T}$ & $\mathrm{T}$ & $\mathrm{C}$ & $\mathrm{T}$ & $\mathrm{T}$ & - & $\mathrm{C}$ & $\mathrm{C}$ & G & $\mathrm{T}$ & G \\
\hline Z. standleyi & $\mathrm{T}$ & $\mathrm{T}$ & A & A & $\mathbf{A}$ & $\mathrm{T}$ & $\mathrm{T}$ & $\mathrm{T}$ & G & $\mathrm{C}$ & $\mathrm{T}$ & $\mathrm{T}$ & - & $\mathrm{C}$ & $\mathrm{C}$ & G & $\mathrm{T}$ & G \\
\hline Z. tuerckheimii & $\mathrm{T}$ & $\mathrm{T}$ & A & A & $\mathrm{C}$ & $\mathrm{T}$ & $\mathrm{T}$ & $\mathrm{T}$ & $\mathrm{T}$ & $\mathrm{C}$ & $\mathrm{T}$ & $\mathrm{T}$ & - & $\mathrm{C}$ & $\mathrm{C}$ & G & $\mathrm{T}$ & G \\
\hline Z. variegata & $\mathrm{T}$ & $\mathrm{T}$ & A & A & $\mathrm{C}$ & $\mathrm{T}$ & $\mathrm{T}$ & $\mathrm{T}$ & $\mathrm{T}$ & $\mathrm{C}$ & $\mathrm{T}$ & $\mathrm{T}$ & - & $\mathrm{C}$ & $\mathrm{C}$ & G & $\mathrm{T}$ & G \\
\hline Z. vazquezii & $\mathrm{T}$ & $\mathrm{T}$ & A & A & $\mathrm{C}$ & $\mathrm{T}$ & $\mathrm{T}$ & $\mathrm{T}$ & $\mathrm{T}$ & $\mathrm{C}$ & $\mathrm{T}$ & $\mathrm{T}$ & - & $\mathrm{C}$ & $\mathrm{C}$ & G & $\mathrm{T}$ & G \\
\hline
\end{tabular}

de mayor dificultad para su identificación taxonómica, lo que básicamente se debe a que las 3 tienen patrones de variación morfológica muy similares que complican su identificación con ejemplares de herbario o en colecciones vivas. Esta situación se agudiza con la ausencia de estructuras femeninas, razón por la que convencionalmente, la identificación de ejemplares pertenecientes a esta especie siempre ha estado asociada a su procedencia geográfica; en este contexto, el análisis con CAOS mostró que para $Z$. polymorpha, especie que se distribuye en la península de Yucatán y Z. loddigesii, existen sitios diagnósticos característicos para cada una (Cuadro 5), por lo que ambas pueden identificarse de manera morfológica y molecular; no obstante, en Z. paucijuga no se encontraron sitios diagnósticos con los loci aquí empleados. En este sentido, se considera que este complejo de especies, al igual que las especies que no presentan sitios diagnósticos (Cuadros 5 y 6) requiere más investigación en el aspecto poblacional, para evaluar detalladamente la variación morfológica y nucleotídica y con ello esclarecer su identificación tanto morfológica como molecular.

Es también predecible que los estudios de filogeografía con datos moleculares (Avise, 2000) abran nuevas perspectivas acerca de los patrones y procesos poblacionales que pudieran explicar la distribución espacial de la diversidad genética y fenotípica actual, no sólo de los complejos sino de todas las especies de Zamia en Megaméxico. En realidad, dichos estudios ya están coexistiendo con los trabajos de códigos de barras para algunos taxa animales (e.g. Linares et al., 2009). Dicha convergencia podría darse 
Cuadro 6. Sitios diagnósticos con ITS2 y matK, para Zamia en Megaméxico

\begin{tabular}{|c|c|c|c|c|c|c|c|c|c|c|}
\hline \multirow[b]{2}{*}{ Taxa } & \multicolumn{7}{|c|}{ ITS 2} & \multicolumn{3}{|c|}{ matK } \\
\hline & 8 & 33 & 248 & 383 & 387 & 398 & 403 & 4 & 316 & 495 \\
\hline Z. cremnophila & $\mathrm{C}$ & $\mathrm{C}$ & $\mathrm{T}$ & $\mathrm{C}$ & $\mathrm{C}$ & $\mathrm{T}$ & G & $\mathrm{C}$ & $\mathbf{C}$ & G \\
\hline Z. fischeri & $\mathrm{C}$ & $\mathrm{C}$ & $\mathrm{T}$ & $\mathrm{C}$ & $\mathrm{C}$ & $\mathrm{T}$ & G & $\mathrm{C}$ & $\mathrm{T}$ & G \\
\hline Z. furfuracea & $\mathbf{A}$ & $\mathrm{C}$ & $\mathrm{T}$ & $\mathrm{C}$ & $\mathbf{A}$ & $\mathbf{A}$ & $\mathrm{A}$ & $\mathrm{C}$ & $\mathrm{T}$ & G \\
\hline Z.herrerae & $\mathrm{C}$ & $\mathrm{C}$ & $\mathrm{T}$ & $\mathrm{C}$ & $\mathrm{C}$ & $\mathrm{T}$ & G & $\mathrm{C}$ & $\mathrm{T}$ & G \\
\hline Z. inermes & $\mathrm{C}$ & $\mathrm{C}$ & $\mathrm{T}$ & $\mathrm{C}$ & $\mathrm{C}$ & $\mathrm{T}$ & G & G & $\mathrm{T}$ & $\mathbf{T}$ \\
\hline Z. katzeriana & $\mathrm{C}$ & $\mathrm{C}$ & $\mathrm{T}$ & $\mathrm{C}$ & $\mathrm{C}$ & $\mathrm{T}$ & G & $\mathrm{C}$ & $\mathrm{T}$ & G \\
\hline Z. lacandona & $\mathrm{C}$ & $\mathrm{C}$ & $\mathrm{T}$ & $\mathrm{C}$ & $\mathrm{C}$ & $\mathrm{T}$ & G & $\mathrm{C}$ & $\mathrm{T}$ & G \\
\hline Z. loddigesii & $\mathrm{C}$ & $\mathrm{C}$ & $\mathrm{T}$ & $\mathrm{C}$ & $\mathrm{C}$ & $\mathrm{T}$ & G & $\mathrm{C}$ & $\mathrm{T}$ & $\mathrm{G}$ \\
\hline Z. paucijuga & $\mathrm{C}$ & $\mathrm{C}$ & $\mathrm{T}$ & $\mathrm{C}$ & $\mathrm{C}$ & $\mathrm{T}$ & G & $\mathrm{C}$ & $\mathrm{T}$ & G \\
\hline Z. polymorpha & $\mathrm{C}$ & $\mathrm{C}$ & $\mathrm{T}$ & $\mathrm{C}$ & $\mathrm{C}$ & $\mathrm{T}$ & G & $\mathrm{C}$ & $\mathrm{T}$ & G \\
\hline Z. prasina & $\mathrm{C}$ & $\mathrm{C}$ & $\mathrm{T}$ & $\mathrm{C}$ & $\mathrm{C}$ & $\mathrm{T}$ & G & $\mathrm{C}$ & $\mathrm{T}$ & G \\
\hline Z. purpurea & $\mathrm{C}$ & $\mathrm{C}$ & $\mathrm{T}$ & $\mathrm{C}$ & $\mathrm{C}$ & $\mathrm{T}$ & G & $\mathrm{C}$ & $\mathrm{T}$ & G \\
\hline Z. soconuscensis & $\mathrm{C}$ & $\mathrm{C}$ & $\mathrm{T}$ & $\mathrm{C}$ & $\mathrm{C}$ & $\mathrm{T}$ & G & C & $\mathrm{T}$ & G \\
\hline Z. spartea & $\mathrm{C}$ & $\mathrm{C}$ & $\mathrm{T}$ & $\mathrm{C}$ & $\mathrm{C}$ & $\mathrm{T}$ & G & $\mathrm{C}$ & $\mathrm{T}$ & G \\
\hline Z. standleyi & $\mathrm{C}$ & $\mathrm{C}$ & $\mathrm{T}$ & $\mathbf{A}$ & $\mathrm{C}$ & $\mathrm{T}$ & G & $\mathrm{C}$ & $\mathrm{T}$ & G \\
\hline Z. tuerckheimii & $\mathrm{C}$ & $\mathbf{A}$ & $\mathrm{C}$ & $\mathrm{C}$ & $\mathrm{C}$ & $\mathrm{T}$ & G & $\mathrm{C}$ & $\mathrm{T}$ & G \\
\hline Z.variegata & $\mathrm{C}$ & $\mathrm{C}$ & $\mathrm{T}$ & $\mathrm{C}$ & $\mathrm{C}$ & $\mathrm{T}$ & G & $\mathrm{C}$ & $\mathrm{T}$ & G \\
\hline Z.vazquezii & $\mathrm{C}$ & $\mathrm{C}$ & $\mathrm{T}$ & $\mathrm{C}$ & $\mathrm{C}$ & $\mathrm{T}$ & $\mathrm{G}$ & $\mathrm{C}$ & $\mathrm{T}$ & G \\
\hline
\end{tabular}

también en especies vegetales como las cícadas de Megaméxico. En cualquier caso, las investigaciones basadas directamente en información molecular permitirán seguir estudiando la variación biológica en general, entre y dentro de especies, para resolver interrogantes biogeográficas, taxonómicas, sistemáticas y de biología evolutiva en las cícadas de Megaméxico.

Finalmente, haciendo uso de los registros actuales de recolecciones botánicas para este grupo, y tomando en cuenta la similitud de los tipos de vegetación que coinciden con las zona de concentración de riqueza y endemismos para el género, se considera que son necesarias más exploraciones botánicas, principalmente en regiones como Montes Azules (Chiapas, México), Alta Verapaz e Izabal en Guatemala, el sureste de Honduras y el noreste de Nicaragua.

Taxonomía alfa y códigos de barras moleculares en Zamia. Como ya se mencionó, Megaméxico es una región biogeográfica con altos niveles de diversidad y endemismo de Zamiaceae, superada únicamente por Australia (Hill et al., 2007; véase Cuadro 8). En esta familia, y en particular en Zamia, los avances en citogenética, ecología y genética de poblaciones (e. g., Vovides et al., 2007) están en vías de ser complementados con el uso de caracteres moleculares, semejantes a los ya utilizados en la inferencia filogenética entre los géneros de cícadas (Treutlein y Wink 2002; Hill et al., 2003; Bogler y Francisco-Ortega 2004; Rai et al., 2003; Chaw et al., 2005; Zgurski et al., 2008). De hecho, ya se han iniciado trabajos de sistemática molecular, análisis filogenéticos y de genética de poblaciones en 3 de los géneros de Zamiaceae del Neotrópico (Ceratozamia Brongn.; González y Vovides, 2002; Dioon Lindl.; Bogler y Francisco-Ortega, 2004, González et al., 2008; Zamia, Caputo et al., 2004; González-Astorga et al., 2006; Limón, 2009).

Entre las líneas de investigación actuales, que abordan el estudio de la diversidad biológica mediante el uso de datos genómicos y con herramientas bioinformáticas, se encuentran los códigos de barras de ADN (Hebert et al., 2003a). Para nuestros propósitos, se puede afirmar que son una herramienta con grandes posibilidades, que complementa, pero no excluye el trabajo de la taxonomía 


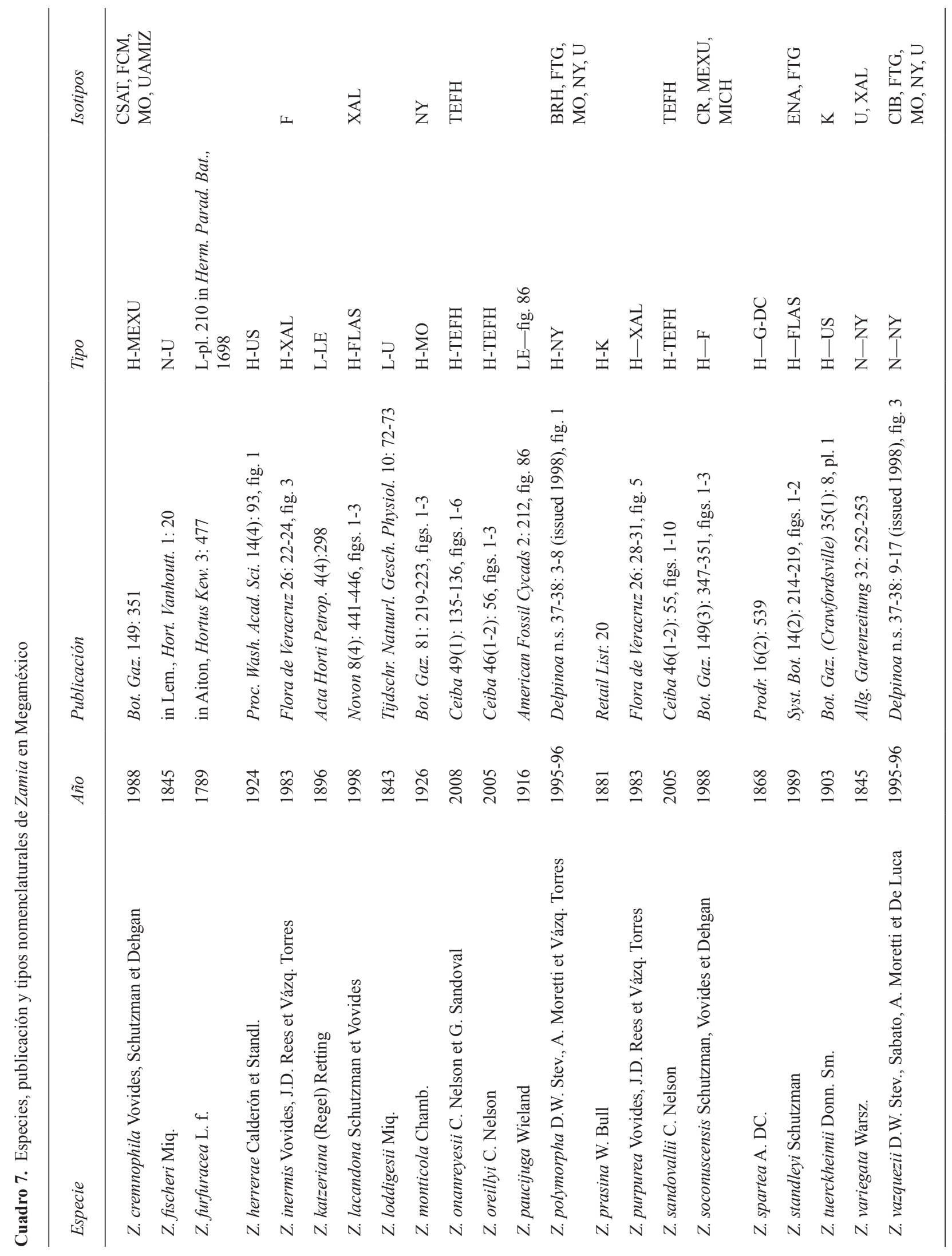


Cuadro 8. Diversidad y endemismos de cícadas en Megaméxico

\begin{tabular}{lcc}
\hline $\begin{array}{l}\text { Géneros de } \\
\text { cícadas }\end{array}$ & Especies descritas & $\begin{array}{c}\text { Especies } \\
\text { endémicas de } \\
\text { Megaméxico 2 }\end{array}$ \\
\hline Ceratozamia & 25 & 25 \\
Dioon & 14 & 14 \\
Zamia & 61 & 22 \\
Total & 100 & 61 \\
\hline
\end{tabular}

tradicional, especialmente en lo que atañe a la identificación de ejemplares ya asignados a un binominal latino válido, es decir, a una hipótesis taxonómica bien fincada en análisis previos de caracteres morfológicos. Aunque es un tema que no está exento de controversia, los códigos de barras moleculares pueden ser un auxiliar en el descubrimiento de nuevas especies, además del papel que desempeñan en el campo de la identificación (Tautz et al., 2003; Seberg et al., 2003; DeSalle, 2006, 2007).

El uso de los códigos de barras en plantas, particularmente en especies del Neotrópico atrae mucho interés debido a la alta diversidad biológica que existe en esta región del planeta. Sin embargo, dada la complejidad involucrada en la selección de regiones del genoma que podrían funcionar como códigos de barras en plantas, y haciendo un análisis crítico de nuestros datos, sólo se encontró un $72 \%$ de éxito en la identificación de las especies de Zamia con la combinación de 4 loci ( $p s b K-p s b I$, atpF-atpH, ITS2 y $m a t K)$. En este sentido, Seberg y Petersen (2009) encontraron que la combinación óptima en la identificación de las especies de Crocus, con el mismo número de loci que en Zamia, fue del 92\% (79/86 spp); lo cual significa que para los resultados del presente estudio es necesaria la búsqueda de otros loci. Dado este contraste entre grupos taxonómicos filogenéticamente distintos, se puede afirmar que hasta el momento las regiones del genoma que parecen ser las mejores candidatas para ser códigos de barras universales en las plantas vasculares (véase, por ejemplo, Lahaye et al., 2008; Ford et al., 2009) no necesariamente funcionan de manera óptima para un subgrupo importante de gimnospermas neotropicales, ni coinciden exactamente con la reciente propuesta de considerar los genes matK y $r b c L$ como códigos de barras universales en plantas (Hollingsworth et al, 2009).

Se considera que la identificación de especies del género Zamia en Megaméxico con los códigos de barras moleculares será de gran utilidad para la corroboración y reforzamiento de las hipótesis individuales correspondientes a las 22 especies de esta región, propuestas en el último tratamiento taxonómico (Nicolalde-Morejón et al., 2009); sin embargo, esto tendría que ser considerado en paralelo con aquellos aspectos que la taxonomía tradicional aún no ha logrado solucionar, en especial al momento de identificar taxa que tengan una amplia variación morfológica entre y dentro de especies y que a su vez presentan una amplia distribución geográfica, como es el caso de $Z$. loddigesii, $Z$. paucijuga y Z. polymorpha (Fig. 1).

En resumen, la posibilidad de contar con atributos diagnósticos moleculares, los cuales funcionarían de manera análoga a los caracteres morfológicos para la descripción de las especies, contribuirá a establecer los límites entre éstas, y en casos excepcionales al descubrimiento de "especies crípticas". En última instancia, se considera que el estudio de la identificación y la delimitación de especies usando el ADN como una nueva fuente de datos tiene su marco conceptual en la "taxonomía integrativa" y el "círculo taxonómico" propuestos por DeSalle et al. (2005).

También es importante enfatizar que un objetivo ulterior para la creación de una biblioteca molecular de referencia hecha de secuencias de nucleótidos para los loci con mayor variabilidad - los códigos de barras de DNA, en sentido estricto- para el género Zamia y los otros géneros de cícadas en Megaméxico es su aprovechamiento por usuarios externos. Un buen ejemplo de utilización de la base de referencias de códigos de barras de ADN es la recuperación de información de ejemplares de decomiso por instancias nacionales o internacionales (como las que se indican en la Convención sobre el Comercio Internacional de Fauna y Flora Silvestres en Peligro de Extinción, o CITES, por sus siglas en inglés) a partir de saqueos ilegales.

\section{Agradecimientos}

Parte de este trabajo fue financiado por la Comisión Nacional para el Conocimiento y Uso de la Biodiversidad (CONABIO) a través del proyecto GE004. El primer autor expresa su agradecimiento a la Red Latinoamericana de Botánica, y en especial a Javier Simonetti, por la beca de doctorado RLB-06-D2. Agradecemos a Dennis W. Stevenson, por facilitarnos imágenes de varios tipos nomenclaturales, a Daniel Piñero, Victoria Sosa, y a dos revisores anónimos por sus comentarios y edición al texto, a Alejandro Espinosa, por su apoyo en los análisis de las secuencias, a Julia Hernández Villa, por todo el apoyo con el trabajo del laboratorio, a Miguel Ángel Pérez Farrera y a Carlos Iglesias, por su ayuda con el trabajo de campo. Reconocemos a los curadores y personal de los herbarios mencionados en el texto, por proporcionarnos las coleccio- 
nes botánicas para el desarrollo de este estudio. Así como también a Julián Pérez, Daniel Hernández, Javier Hernández, Joel López y Genaro Justo, personal técnico del Jardín Botánico Francisco Javier Clavijero.

\section{Literatura citada}

Avise, J. C. 2000. Phylogeography: The History and Formation of Species. Harvard

University Press, Cambridge. 464 p.

Balduzzi, A. P., P. De Luca y S. Sabato. 1982. A phytogeographical approach to

the New World Cycads. Delpinoa, s.n.:23-24.

Bogler, D. J. y J. Francisco-Ortega. 2004. Molecular systematic studies in cycads:

evidence from trnL intron and ITS2 rDNA sequences. Botanical Review 70:260-273.

Caputo, P., S. Cozzolino, P. De Luca, A. Moretti y D. W. Stevenson. 2004.

Molecular phylogeny of Zamia (Zamiaceae). In Cycad classification: concepts

and recommendations, T. Walters y R. Osborne (eds.). CABI, Wallingford. p. 149-157.

CBOL Plant Working Group. P. M., Hollingsworth, L. L. Forrest, J. L. Spouge, M. Hajibabaei, S. Ratnasingham, M. van der Bank, M. W. Chase, R. S. Cowan, D. L. Erickson, A. J. Fazekas, S. W. Graham, K. E. James, Ki-Joong Kim, W. J. Kress, H. Schneider, J. van AlphenStahl, S. C. H. Barrett, C. van den Berg, D. Bogarin, K. S. Burgess, K. M. Cameron, M. Carine, J. Chacón, A. Clark, J. J. Clarkson, F. Conrad, D. S. Devey, C. S. Ford, T. A. J. Hedderson, M. L. Hollingsworth, B. C. Husband, L. J. Kelly, P. R. Kesanakurti, J. S. Kim, Y. D. Kim, R. Lahaye, H. L. Lee, D. G. Long, S. Madriñán, O. Maurin, I. Meusnier, S. G. Newmaster, Chong-Wook Park, D. M. Percy, G. Petersen, J. E. Richardson, G. A. Salazar, V. Savolainen, O. Seberg, M. J. Wilkinson, D. K. Yi y D. P. Little. 2009. A DNA barcode for land plants. Proceedings of the National Academy of Sciences 106:12794-12797.

Chaw, S. M., T. W. Walters, C. C. Chang, S. H. Hu y S. H. Chen. 2005. A phylogeny of cycadas (Cycadales) inferred from chloroplast matK gene, trnK intron, and nuclear rDNA ITS region. Molecular Phylogenetics and Evolution 37:214-234.

DeSalle, R., M. G. Egan y M. Siddall. 2005. The unholy trinity: taxonomy, species delimitation and DNA barcoding. Philosophical Transactions of the Royal Society B 360:19051916.

DeSalle, R. 2006. Species discovery versus species identification in DNA barcoding efforts: response to Rubinoff. Conservation Biology 20:1545-1547.

DeSalle, R. 2007. Phenetic and DNA taxonomy; a comment on Waugh. Bioessays 29:1289-1290.
Fazekas, A.J., K. S.Burgess, P. R. Kesanakurti, S. W. Graham, S. G. Newmaster, B. C. Husband, D. M. Percy, M Hahibabaei y S. C. H. Barrett. 2008. Multiple multilocus DNA barcodes from the plastid genome discriminate plant species equally well. PLoS ONE 3:7-e2802.

Ford, C. S., K. L. Ayres, N. Toomey, N. Haider, J. van Alphen Stahl, L. J. Kelly, N. Wikström, P. M. Hollingsworth, R. J. Duff, S. B. Hoot, R. S. Cowan, M. W. Chase, M. J. Wilkinson. 2009. Selection of candidate coding DNA barcoding regions for use on land plants. Botanical Journal of the Linnean Society 159:1-11.

González, D. y A. P. Vovides. 2002. Low intralineage divergence in Ceratozamia (Zamiaceae) detected with nuclear ribosomal DNA ITS and chloroplast DNA trnL-F non coding region. Systematic Botany 27:654-661.

González, D., A. P. Vovides y C. Bárcenas. 2008. Phylogenetic relationships of the neotropical genus Dioon (Cycadales, Zamiaceae) based on nuclear and chloroplast DNA sequence data. Systematic Botany 33:229-236.

González-Astorga, J., A. P. Vovides, P. Octavio-Aguilar, D. Aguirre-Fey, F. Nicolalde-Morejón y C. Iglesias. 2006. Genetic diversity and structure of the cycad Zamia loddigesii Miq. (Zamiaceae): implications for evolution and conservation. Botanical Journal of the Linnean Society 152:533-544.

Hall, T. A. 1999. BioEdit: a user-friendly biological sequence aligment editor and analysis program for Windows 95/98/ NT. Nucleic Acids Symposium Series 41:95-98

Hebert, P. D. N., A. Cywinska, S. L. Ball y J. R. deWaard. 2003. Biological identifications through DNA barcodes. Proceedings of the Royal Society of London B 270:313-321.

Hebert, P. D. N. y T. R. Gregory. 2005. The promise of DNA barcoding for taxonomy. Systematic Biology 54:852-859.

Hill K. D., M. W. Chase, D. W. Stevenson, H. G. Hills y B. Schutzman. 2003. The families and genera of cycads: a molecular phylogenetic analysis of Cycadophyta based on nuclear and plastid DNA sequences. International Journal of Plant Sciences 164:933-948.

Hill, K. D., D. W. Stevenson y R. Osborne. 2007. The world list of cycads/La lista mundial de cícadas. Memoirs of the New York Botanical Garden 97:454-483.

Holdridge, L. R. 1987. Ecología basada en zonas de vida. Instituto Interamericano de Cooperación para la Agricultura, San José. 216 p.

Lahaye, R., M. van der Bank, D. Bogarin, J. Warner, F. Pupulin, G. Gigot, O. Maurin, S. Duthoit, T. G. Barraclough y V. Savolainen. 2008. DNA barcoding the floras of biodiversity hotspost. Proceedings of the National Academy of Sciences 105:2923-2928.

Limón, F. L. 2009. Genética de Poblaciones de Zamia furfuracea L. f. (Zamiaceae); una cícada endémica al estado de Veracruz, México. Tesis, Facultad de Biología, Universidad 
Veracruzana, Xalapa. 58 p.

Linares, M. C., I. D. Soto-Calderón, D. C. Lees y N. M. Anthony. 2009. High mitochondrial diversity in geographically widespread butterflies of Madagascar: A test of the DNA barcoding approach. Molecular Phylogenetics and Evolution 50:485-495.

Marchant, C. J. 1968. Chromosome patterns and nuclear phenomena in the cycad families Stangeriaceae and Zamiaceae. Chromosoma 24:100-134.

Miquel, F. A. W. 1842. Monographia Cycadearum, t. 4-5. Trajecti ad Rhenum, Utrecht p. 32-48.

Miquel, F. A. W. 1851. Cycadeae quaedam americanae, Partim Novae. Nederl. Inst. Verh. Erste K1. (series 3) 4:181-189.

Miquel, F. A. W. 1861. Prodromus systematics cycadearum. C. v. d. Post Jr., Utrecht. 35 p.

Moretti, A. y S. Sabato. 1984. Karyotype evolution by centromeric fission in Zamia (Cycadales). Plant Systematics and Evolution 146:215-223.

Moretti, A. 1990. Karyotypic data on North and Central American Zamiaceae (Cycadales) and their phylogenetic implications. American Journal of Botany 77:1016-1029.

Moretti, A., P. Caputo, L. Gaudio, y D. W. Stevenson. 1991. Intraspecific chromosome variation in Zamia (Zamiaceae, Cycadales). Caryologia 44:1-10.

Nicolalde-Morejón, F. 2007. Taxonomía, distribución y estado de conservación de Zamia en Ecuador. Memoirs of the New York Botanical Garden 97:45-63.

Nicolalde-Morejón, F., A. P. Vovides, D. W. Stevenson y V. Sosa. 2008. The identity of Zamia katzeriana and Zamia verschaffeltii (Zamiaceae). Brittonia 60:38-48.

Nicolalde-Morejón, F., A. P. Vovides, D. W. Stevenson. 2009. Taxonomic revision of Zamia in Mega-Mexico. Brittonia.61:301-335..

Norstog, K. y T. J. Nicholls. 1997. The Biology of the Cycads. Cornell University Press, Ithaca, Nueva York. 363 p.

Pennisi, E. 2007. Wanted: a barcode for plants. Science 318: 190191.

Rai, H. S., H. E. O'Brien, P. A. Reeves, R. G. Olmstead y S. W. Graham. 2003. Inference of higher-order relationships in the cycads from a large chloroplast data set. Molecular Phylogenetics and Evolution 29:350-359.

Rzedowski, J. 1978. Vegetación de México. Limusa, México, D.F. 431 p.

Rzedowski, J. 1991. El endemismo en la flora fanerogámica mexicana: una apreciación analítica preliminar. Acta Botanica Mexicana 15:47-64.

Sabato, S. 1990. West Indian and South American cycads. Memoirs of the New York Botanical Garden 57:173-185.

Sarkar, I. N., P. J. Planet, R. DeSalle. 2008. CAOS software for use in character-based DNA barcoding. Molecular Ecology Resources. 8:1256-1259.

Sass, Ch., D. P. Little, D. W. Stevesnon, Ch. D. Specht. 2007.
DNA barcoding in the

Cycadales: testing the potential of proposed barcoding markers for species Identification of cycads. PLoS ONE. 11: e1154.

Schuster, J. 1932. Cycadaceae. Das Pflanzenreich 99:1-168. Wilhelm Engelmann, Leipzig.

Seberg, O., J. Ch. Humphries, S. Knapp, D. W. Stevenson, G. Petersen, N. Scharff y N. M. Andersen. 2003. Shortcuts in systematics? A commentary on DNA-based taxonomy. 2003. Trends in Ecology and Evolution 18:63-65.

Seberg, O y G. Petersen. 2009. How many loci does it take to DNA barcode a Crocus? PLoS ONE 42: e4598.

Stevenson D. W. 1987. The West Indian zamias. Fairchild Tropical Garden Bulletin 42:23-27.

Stevenson D. W. 1991a. Flora of the Guianas. Serie. A. Fascicule 9:7-11.

Stevenson D. W. 1991b. The Zamiaceae in the Southeastern United States. Journal of the Arnold Arboretum, Supplemental Series 1:367-383.

Stevenson D. W. 1992. A formal classification of the extant cycads. Brittonia 44:220-223

Stevenson D. W. 1993. The Zamiaceae in Panama with comments on phytogeography and species relationships. Brittonia 45:1-16.

Stevenson D. W. 2001a. Orden Cycadales. Flora de Colombia. Monografía 21. Unibiblos, Bogotá D.C. 92 p.

Stevenson D. W. 2001b. Zamiaceae. Flora Nicaragua 1:6-7.

Stevenson D. W. 2004. Zamiaceae of Bolivia, Ecuador, and Peru. In Cycad classification: concepts and recommendations, $\mathrm{T}$. Walters y R. Osborne (eds.). CABI, Wallingford. p. 173-194.

Stevenson D. W. y S. Sabato. 1986. Typification of names in Zamia L. and Aulacophyllum Regel. (Zamiaceae). Taxon 35:134-144.

Taylor, A. S., J. L. Haynes y G. Holzman. 2009. Taxonomical, nomenclatural and biogeographical relevations in the Zamia skinneri complex of Central America (Cycadales: Zamiaceae). Botanical Journal of the Linnean Society 158:399-429.

Thompson, J.D., T. J. Gibson, F. Plewniak, F. Jeanmougin y D. G. Higgins. 1997. The ClustalX windows interface: flexible strategies for multiple sequence alignment aided by quality analysis tool. Nucleic Acids Research 25:4876-4882.

Toledo, V. M. 1982. Pleistocene changes of vegetation in tropical Mexico. In Biological diversification in the tropics, G. T. Prance (ed.). Columbia University Press, New York. p. 93111.

Treutlein, J. y M. Wink. 2002. Molecular phylogeny of cycads inferred from $r b c \mathrm{~L}$ sequences. Naturwissenschaften 89:221225.

Tautz, D., P. Arctander, A. Minelli, R. H. Thomas y A. P. Vogler. 2003. A plea for DNA taxonomy. Trends in Ecology and Evolution 18:70-74.

Vovides, A. P. 1983. Systematics studies on the Mexican Zamiaceae I. Chromosome numbers and karyotypes. 
American Journal of Botany 70:1002-1006.

Vovides, A. P. y M. Olivares. 1996. Karyotype polymorphism in the cycad Zamia loddigesii (Zamiaceae) of the Yucatan peninsula, Mexico. Botanical Journal of the Linnean Society 120:77-83.

Vovides, A. P., J. González-Astorga, M. A. Pérez-Farrera, D. González, C. Bárcenas y C. Iglesias. 2007. The cycads of
Mexico: 25 years of research and conservation. Memoirs of the New York Botanical Garden 97:611-641.

Zgurski, J. M., H. S. Rai, Q. M. Fai, D. J. Bogler, J. FranciscoOrtega y S. W. Graham. 2008. How well do we understand the overall backbone of cycad phylogeny? 125 new insights from a large, multigene plastid data set. Molecular Phylogenetics and Evolution 47:1232-1237. 
